\title{
Exploring the Impact of Green Practices on Employees' Green Behavior outside the Organization
}

\author{
Nahdia Asri Rabbani \\ University of Groningen
}

\begin{abstract}
In light of investigating the green behavior of employees outside the organization, it is critical that both their work and non-work roles be taken into account in determining the extent to which their firm shapes this mindset. This study concerns the green behavior of employees based on a western-born multinational organization rooted in its pro-sustainable nature. The firm serves as one of the catalysts fueling the "go-green" movement in Indonesia - an emerging economy where sustainability is scantly discussed. This study aids in recognizing the underlying effectiveness of green internal practices in real-life context, and contributes to extant literature by filling the gap in covering Green Human Resource Management application in emerging economies. Additionally, it invites Indonesian citizens and Human Resource practitioners to implement green-forward initiatives, considering the inherent benefits and potential gains presented. Through the means of six in-depth interviews, this qualitative study involved bilingual translations of verbatim transcripts, followed by subsequent analysis using the Atlas.ti 8 program. In turn, the study provided illustrious results. The participants showed eagerness in continuously performing sustainable acts beyond office doors, integrating the newly-obtained knowledge and learnt habits into their daily lives. Even without formal insistence from the organization's side, the employees understand the urgency and significance behind sustainable actions, and are willing to continue taking part in the movement in their own ways. Despite Indonesia's limited institutional infrastructure and lack of support in terms of sustainability, their keenness to pursue a more sustainable outlook in life remains strong.
\end{abstract}

Keywords: Emerging economy; employee-level study; Green Human Resource Management; green work-life balance; Indonesia 